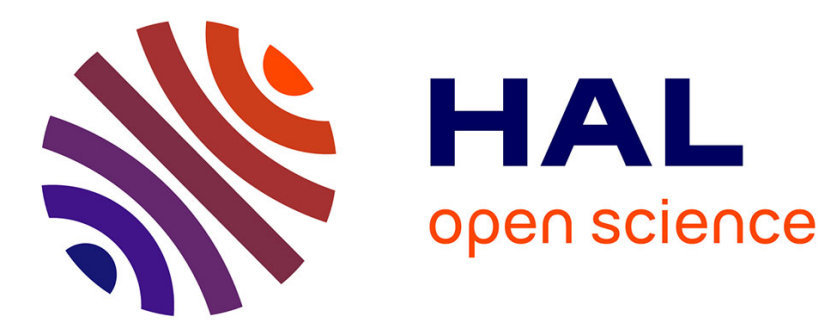

\title{
Chemical compounds as trigger factors of immediate contact skin reactions \\ Elena Giménez-Arnau
}

\section{To cite this version:}

Elena Giménez-Arnau. Chemical compounds as trigger factors of immediate contact skin reactions. Contact Urticaria Syndrome 2nd Edition, 2015. hal-02126155

\section{HAL Id: hal-02126155 \\ https://hal.science/hal-02126155}

Submitted on 10 May 2019

HAL is a multi-disciplinary open access archive for the deposit and dissemination of scientific research documents, whether they are published or not. The documents may come from teaching and research institutions in France or abroad, or from public or private research centers.
L'archive ouverte pluridisciplinaire HAL, est destinée au dépôt et à la diffusion de documents scientifiques de niveau recherche, publiés ou non, émanant des établissements d'enseignement et de recherche français ou étrangers, des laboratoires publics ou privés. 


\title{
Chemical Compounds as Trigger Factors of Immediate Contact Skin Reactions
}

\author{
ELENA GIMÉNEZ-ARNAU
}

Laboratoire de Dermatochimie

Institut de Chimie de Strasbourg (CNRS UMR 7177)

Université de Strasbourg

4, Rue Blaise Pascal

67081 Strasbourg

France

Tel: +33368851525

Fax: +33 368851527

E-mail: egimenez@unistra.fr

Key words: Immediate skin reactions, contact urticaria, non-immunological, immunological, occupational, low molecular weight compounds. 


\section{INTRODUCTION}

Immediate contact skin reactions manifest as Contact Urticaria (CoU), Contact Urticaria Syndrome (CUS) and Protein Contact Dermatitis (PCD). These pathologies are characterized by the immediate skin development of itchy flares, wheals and/or dermatitis, following external contact with a substance (1).

CoU usually appears within 30 minutes, and clears completely within hours, without residual signs of irritation. Fisher defined it in 1973, even if this phenomenon had been recognized for many years (2). CoU is a very frequent pathology, and an ever-expanding list of causes, substances ranging from simple chemicals to macromolecules, has been reported. Mostly proteins (molecular weight $10000 \mathrm{Da}$ to several hundred thousands), but also chemical compounds of low molecular weight (LMW) $(<1000$ Da) are involved. The present chapter will focus mainly on these chemical compounds of LMW.

In order to review the LMW chemical agents responsible for immediate contact skin symptoms, it is first necessary to remind the defined categories of $\mathrm{CoU}$ according to the underlying mechanism(s) involved. Basically, CoU is classified as non-immunological or immunological. A third category exists for reactions with mixed features or undetermined pathomechanisms (3). Non-immunological CoU (NICoU) is the most common form of the disease, occurring without prior exposure to an eliciting substance, that means without previous sensitization. Substances inducing NICoU are frequently encountered in our environment as preservatives, fragrances and flavorings in cosmetics, toiletries, topical medicaments and foodstuffs $(4,5)$. The pathogenesis is not clearly understood but it appears to involve the release of vasogenic mediators without involvement of immunological processes. Due to the lack of response to antihistamines and the positive response to acetylsalicylic acid and non-steroidal anti-inflammatory drugs, it has been proposed that the physiopathology involves prostaglandin release from the epidermis rather than histamine release from the mast cells, as previously assumed $(6,7)$. On the other hand, immunologic $\mathrm{CoU}(\mathrm{ICoU})$ is a type I hypersensitivity reaction, mediated by allergenspecific immunoglobulin E (IgE) in previously sensitized individuals (3). In this case, the release of histamine is the major mechanism of action seen. The mechanism following skin challenge includes allergen penetration through the epidermis, binding to $\operatorname{IgE}$ on mast cells, causing degranulation and release of histamine and other vasoactive substances such as prostaglandins, leukotrienes and kinins (8). Again, a large number of causes have been documented as causing ICoU. Many are plant or animal proteins (9). However, many LMW chemicals including drugs, biocides and preservatives, metals or industrial compounds can also produce ICoU. Finally, a third category exists for substances that show mixed features of $\mathrm{NICoU}$ and $\mathrm{ICoU}$, or where the mechanism remains unclear. The bleaching agent 
ammonium persulfate is a classic example. Although the clinical picture looks like an IgE-mediated reaction, such antibodies against ammonium persulfate have not been identified $(5,10)$. However, this third category is much less common and will not be treated herein.

Tables 1 and 2 resume the most reported LMW chemical agents producing immediate nonimmunologic and immunologic skin reactions $(1,11)$.

\section{CHEMICALS AND NON-IMMUNOLOGICAL REACTIONS}

Chemical compounds mainly described as triggering immediate contact reactions and NICoU are listed in Table 1. Many of these chemicals are used in fragrances, in cosmetic products, as biocides or preservatives, and as drugs or topical medications. Though, there are also other miscellaneous chemicals and metals responsible for these reactions. Most individuals react to these substances with local erythema and/or edema within 45 min after application, albeit with widely varying intensities of skin reaction (12).

\section{Fragrances and cosmetics ingredients}

NICoU reactions to fragrances and to cosmetics ingredients are well known (13). NICoU has been reported for example to some of the constituents of the Fragrance Mix I (FMI), and to balsam of Peru (14). However, clinical relevance must be carefully examined because individuals may develop simple NICoU or contact urticaria associated with delayed hypersensitivity. Indeed, the components of the FMI ( $\alpha$-amyl cinnamic aldehyde, cinnamic aldehyde, cinnamic alcohol, eugenol, isoeugenol, geraniol, hydroxycitronellal, oak moss) are potent skin sensitizers responsible for delayed type allergic contact dermatitis. Actually, the FMI, developed in the late 1970s, and the Fragrance Mix II developed in 2005, are the most valuable screening tools for the detection of delayed hypersensitivity to fragrances (15, 16). Safford et al. conducted a study on 20 patients positive to the FMI in 48 hours and classified the FMI ingredients according to the decreasing ability to induce contact urticaria as follows: cinnamic

aldehyde, cinnamic alcohol, isoeugenol, hydroxycitronellal and geraniol (17). Cinnamic aldehyde and cinnamic alcohol were the strongest urticaria inducers for non-allergic patients. Contact urticaria from cinnamic aldehyde has been reported by several authors (4), leading even to anaphylaxis (18). Among the many components of balsam of Peru, cinnamic aldehyde is described as well as the strongest agent inducing NICoU, followed by cinnamic acid, benzoic acid and benzaldehyde (19). Cinnamic aldehyde is the main component of cassia oil (ca. 90\%) and cinnamon bark oil (ca. 75\%). It is also the main component of artificial cinnamon oil. Smaller quantities are found in many other essential oils. In 
nature, the trans isomer is predominant. It is a yellowish liquid with a characteristic spicy odor, strongly reminiscent of cinnamon. Being an $\alpha, \beta$-unsaturated aldehyde, it undergoes many reactions of which hydrogenation to cinnamic alcohol. Its oxidation occurs readily on exposure to air yielding cinnamic acid. Cinnamic acid has been also used in perfumery, as a flavoring ingredient in pharmaceutical preparations and in food products. Forsbeck and Skog found contact urticaria from cinnamic acid 5\% in petrolatum in three out of five patients with immediate skin reactions to balsam of Peru (19). The unsaturated terpene alcohol geraniol, a colorless liquid with a flowery-rose like odor, gave a patch test reaction after $20 \mathrm{~min}$ of application in a woman suffering from recurring oedema in the lips and neck. The test with a perfume containing geraniol gave generalized urticaria (20). CUS at stage IV has been reported in the case of people applying sunscreen and self-tanning products, being benzophenone-3 the major cause (21). Benzophenone-3, also named oxybenzone, is often incorporated into sunscreen formulations to offer enhanced UVA protection because its absorption spectrum extends to less than $350 \mathrm{~nm}$. In toothpaste and in a make-up remover, menthol, belonging to the family of monoterpenols, was described as the reason for urticaria reactions, plus cephalgia, in a woman placed in a context of generalized urticaria (22). Symptoms disappeared with total eviction of menthol.

\section{Biocides and preservatives}

Many compounds used as preservatives, such as imidazolidinyl urea, bronopol and sorbic acid, have been shown to induce positive reactions at patch test after $45 \mathrm{~min}$ in a population of 50 patients (23). Contact urticaria from sorbic acid is however thought to be rare, and only few reports can be found in the literature. Some authors described that creams and shampoos containing sorbic acid caused erythema, slight itching and oedema sometimes $(24,25)$. Like sorbic acid, benzoic acid is a natural preservative, having antibacterial and antifungal properties. Present also in balsam of Peru, it induced contact urticaria at $5 \%$ in patients with immediate contact reactions to balsam of Peru (19). It has also been commonly used as a preservative in acidic food products. Thus, it was reported in a published study that benzoic and sorbic acid could elicit NICoU at concentrations in use in salad dressing in 18 of 20 school children (26). In the case of free formaldehyde, for which bactericidal and fungicidal properties confer it a place of choice for preservation of cosmetics, its use has been reduced because of the bad press it has received as an irritant, sensitizer and potential carcinogen (27). Formaldehyde is known to be a strong-ubiquitous skin sensitizer, including from non-cosmetic sources of contact. Because of this, exposure to formaldehyde in the EU is subject to restrictions. Free formaldehyde may be used as a preservative in all cosmetic products (maximum authorized concentration $0.2 \%$, except 
$0.1 \%$ in products for oral hygiene) except aerosol cosmetics. Annex VI of the Cosmetics Directive 76/768 EC further stipulates that all finished products containing formaldehyde or substances that release formaldehyde must be labelled with the warning "contains formaldehyde" where the concentration of free formaldehyde in the finished product exceeds $0.05 \%$ (28). As an alternative, chemical compounds that slowly release formaldehyde in the presence of water and under usage conditions, the so-called formaldehyde-releasers, are commonly employed as preservatives in cosmetics (water based preparations) instead of free formaldehyde. Examples are bronopol and imidazolidinyl urea. Unfortunately, many formaldehyde-releasers used in cosmetics are also skin sensitizers, due to released formaldehyde but also to reactive intermediates other than formaldehyde that could be involved in the formation of the hapten-protein antigenic complex, a key step of the sensitization process, and thus explaining their sensitizing potential per se (29). Even if it is a strong sensitizer, reported immediate reactions to formaldehyde are mainly classified as NICoU because they seem not to be mediated by $\operatorname{IgE}$ (30). However, there is still no consensus in the reports that have appeared as to whether the mechanism is immunological or non-immunological (31). Contact urticaria to other biocides such as $p$-chloro-m-cresol, benzyl alcohol, 2-phenoxyethanol and polyethylene glycols, used as preservatives in a wide number of cosmetics and topical preparations, has also been reported (32-35). Contact urticaria from alcohols was reviewed in the 90s, with cases classified as nonimmunological and some as immunological based on open skin tests (36).

\section{Drugs}

Many drugs can also provoke immediate skin reactions. They include mainly antibiotics, because direct contact of nurses and health care personnel during their preparation, or employees during the production in the pharmaceutical industry. Penicillins and cephalosporins are the most incriminated. All of them seem to have an immunological physiopathology and will be discussed below. For most of the other drugs reported, observed immediate contact reactions cannot be definitely classified as nonimmunological or immunological. Often, skin tests do not allow distinguishing between an IgE dependent reaction and a non-specific histamine release, and research of specific IgE by using the radioallergosorbent test (RAST) is only available for some drugs. One example is given by lidocaine. It is a common amino amide-type local anaesthetic applied topically, and the most important class 1B antiarrhythmic drug applied intravenously. An immediate positive patch test and prick test demonstrated its involvement in the simultaneous presence of contact urticaria and allergic contact dermatitis in the same patient $(37,38)$. Ketoprofen, an important cause of photocontact dermatitis, has 
also been described as responsible for contact urticaria (39). Other immediate reactions have been observed in personnel of psychiatry services during the manipulation of phenothiazines, antipsychotic drug related to the thiazine class of heterocyclic compounds, such as chlorpromazine and promethazine (40).

To end with this section, among the many professional areas where case reports of contact urticaria have been reported, workers of pharmaceutical and chemical industries are of considerable concern. They are in contact with highly reactive substances (some listed in Table 1) used for synthesis for example that have been also described as inducers of immediate skin reactions.

The pathogenesis of NICoU to all these chemicals is not clearly defined. Different urticariogens may act by different mechanisms. For example, dimethyl sulfoxide can both damage blood vessels and cause mast cell degranulation. However, antihistamines do not inhibit reactions to dimethyl sulfoxide and other NICoU triggering agents, whilst acetylsalicylic acid and non-steroidal anti-inflammatory drugs do, both orally and topically, suggesting a role for prostaglandins $(6,7,41)$. Release of prostaglandin $\mathrm{D}_{2}$ without concomitant histamine release has been shown for instance following topical application of sorbic acid and benzoic acid $(42,43)$.

\section{CHEMICALS AND IMMUNOLOGICAL REACTIONS}

ICoU is an immediate type 1 hypersensitivity reaction, occurring in patients who have specific $\operatorname{IgE}$ against the agent(s) eliciting contact urticaria. ICoU needs sensitization, and will appear after repeated contacts. It is more frequent in people with previous atopic symptoms. The allergen reacts with the IgE at the surface of mast cells and basophiles and provokes the release of histamine and other vasoactive substances, except in rare cases where $\operatorname{IgG}$ or $\operatorname{IgM}$ have been incriminated. The consequences are potentially more serious than for NICoU, as reactions may not remain localized to the area of contact, and generalized urticaria, or even involvement of organs such as the respiratory and gastrointestinal tract may follow, and end with anaphylactic shock. The commonest agents inducing ICoU are food proteins (animal or vegetal), animal proteins, and natural rubber latex, and have been largely reviewed $(9,44)$. However, chemicals of LMW can also induce ICoU and are listed in Table 2. They are very often present in drugs, cosmetics (45) and industrial preparations. There are extensive lists of proteins and chemicals reported as causing ICoU, only a part of them being reported as occupational $(3,11,44)$. Most publications about contact urticaria concern case reports or little series and epidemiological 
studies are scarce. However, some data indicate that ICoU is not rare, although frequently underestimated.

Diagnosis of occupational contact urticaria is based on the patient's previous medical history, chronology and description of skin symptoms. With exception to substances inducing NICoU, skin tests are generally necessary for diagnosis. An order of skin investigations for evaluation of immediate responses has been suggested $(3,46)$. Skin prick tests with fresh material or commercial reagents is the gold standard diagnostic test (8). But the ultimate evidence corroborating that a compound is responsible for ICoU is the measurement of specific IgE in the serum of the patient by the radioallergosorbent RAST test whenever possible. The RAST is a radioimmunoassay test to detect specific IgE antibodies to a suspected or known agent (protein, chemical compound) responsible of ICoU. The patient's serum is incubated with the agent bound to a solid phase, and the amount of specific $\operatorname{IgE}$ recognising and binding to the agent is quantified with radiolabelled anti-IgE (47). Determination of specific IgE by RAST will confirm type I hypersensitivity, but their ordinary detection is restricted to some compounds, particularly when they are non-proteinaceous. In this section, some examples reported in the literature are given.

\section{Evidence on IgE-mediated urticaria to low molecular weight compounds: reported examples Biocides and preservatives}

Chloramine is commonly used as a sterilizer, disinfectant and chemical reagent. It has been described as an occupational hazard for pharmaceutical workers, nurses and cleaners. Goossens et al. reported the first case of immediate positive epicutaneous tests to chloramine powder solutions used by a nurse (48). All skin tests performed on the patient were suspicious of an immediate type reaction. The immunological nature of the clinical manifestations was investigated by RAST on serum of the patient. High levels of IgE antibodies to chloramine were found, those previously bound to human serum albumin (HSA). The clinical manifestation on the patient was confirmed by radioimmunoassay and classified as a stage 3 contact urticaria syndrome. Chloramine is often confused with chloramine-T as both are employed as sterilizer, antiseptic and disinfectant agents. However, they are two different chemicals. Chloramine-T is a $N$-chlorinated deprotonated sulfonamide, white powder, contrarily to chloramine, a simple monochlorinated amine $\left(\mathrm{NH}_{2} \mathrm{Cl}\right)$ which is a colorless liquid usually handled as a diluted aqueous solution. Allergic asthma caused by chloramine-T is well known and the reactions are IgE mediated. Kramps et al. were able to demonstrate the presence of specific IgE antibodies in the serum of asthmatic-chloramine $\mathrm{T}$ allergic patients (49). However, skin symptoms of $\operatorname{IgE}$ dependent 
contact urticaria have also been reported in the case of a hospital bath attendant in Finland. The performed RAST to chloramine-T showed specific IgE antibodies with values being defined as positive (50).

Chlorhexidine, a cationic chlorophenyl-biguanide, is also an effective antiseptic and disinfectant, that can trigger IgE-mediated type I hypersensitivity reactions in sensitized individuals (51). Many health care workers are exposed to hand washes containing chlorhexidine. In the United Kingdom, four cases of occupational IgE-mediated allergy to chlorhexidine were identified, the diagnosis being made on an appropriate clinical history with positive serum specific IgE to chlorhexidine and/or positive skin prick testing (52).

Interestingly, formaldehyde, described already in the previous NICoU section, is a primary skin sensitizer inducing allergic contact dermatitis also suspected to induce ICoU. There have been few reports on allergy to formaldehyde associated with $\operatorname{IgE}$, and single cases of formaldehyde-specific $\operatorname{IgE}$ mediated urticaria exist in the literature (53). Thus, probably formaldehyde should be classified as a substance that shows mixed features of NICoU and ICoU, as the mechanism remains unclear.

\section{Drugs}

Antibiotics are very often associated to ICoU, such as penicillin (54). Allergic reactions are estimated to occur in approximately $2 \%$ of patients treated with penicillin. Most of these are maculopapular or urticarial rashes. Severe reactions to penicillin such as anaphylaxis can occur and are potentially life threatening. Penicillin belongs to the $\beta$-lactam group of antibiotics. All penicillin antibiotics contain a common nucleus (6-aminopenicillanic acid) composed of a $\beta$-lactam ring and a thiazolidine ring, this complex connected to a side chain. An intact $\beta$-lactam ring is necessary for bactericidal activity, and the side chain determines the spectrum of antibacterial activity, the susceptibility to destruction when exposed to acids and $\beta$-lactamases, and pharmacokinetics properties. Penicillin is a hapten and becomes immunogenic only when it binds to a protein. The $\beta$-lactam ring covalently binds to lysine residues of proteins and forms the penicilloyl group, known as the "major determinant" because it is the major penicillin metabolic product. Penicillin metabolites also form disulfide bonds with sulfhydryl groups of cysteine, producing the "minor determinants", so called because they are formed in smaller

quantities. Thus, immediate allergic reactions to penicillin are mediated through IgE antibodies against either the major or minor determinants or both.

Based on this, penicillin skin testing techniques have been developed demonstrating the presence or absence of specific IgE antibodies against major and minor penicillin determinants. The use of 
benzylpenicilloyl-poly-L-lysine can test IgE antibodies against major determinants. Histamine is used as a positive control, and saline is used as a negative control. Skin detection of serum IgE specific for major penicillin determinants has a high positive predictive value but fails to identify patients with penicillin allergy. It has been suggested that, ideally, skin testing to major and minor penicillin determinants would improve diagnosis. Methods of preparation of reagents for minor determinants have been published, and penicillin $\mathrm{G}$ has been used as a partial source of minor determinants. Today, alternatives to benzylpenicilloyl-poly-L-lysine and minor determinant mixtures are commercially available for skin testing (55). Penicillin skin testing is believed to be safe if done properly, although severe reactions such as anaphylaxis have been reported, these produced because violation of the test protocols such as doing intracutaneous testing without first doing prick testing.

Concerning the RAST and the enzyme-linked immunosorbent assay (ELISA), they detect IgE antibodies to the major penicillin determinant only, with a sensitivity of approximately $80 \%(56)$.

The immunologic responses to different determinants of benzylpenicillin, amoxicillin and ampicillin have been also reported by using these methodologies (57). One study reported that the sensitization rate by skin prick and intradermal tests to benzylpenicilloyl-poly-L-lysine and a mixture of minor antigenic determinants was $12 \%$ in 83 asymptomatic Turkish nurses (58). Prick and intradermal penicillin sensitivity tests reported rates of $22 \%$ for benzylpenicilloyl-poly-L-lysine, $21 \%$ for minor determinant mixture, $43 \%$ for amoxicillin, and $33 \%$ for ampicillin in patients with a clinical history of urticaria and/or anaphylaxis (59).

After penicillins, cephalosporins are the most important $\beta$-lactams inducing IgE mediated reactions. Responses may be selective or cross-react with common $\beta$-lactam determinants. Unlike determinants derived from benzylpenicillin, cephalosporin allergenic determinants have not been well identified but it is possible to monitor serum specific IgEs. In a cross-reactivity study conducted with a group of Italian subjects who had immediate allergic reactions to one or more cephalosporins (ceftriaxone, cefotaxime, ceftazidime, cefuroxime), IgE evaluation was performed by skin tests and RASTs with the responsible drugs as well as to classic penicillin determinants (60). Prick and intradermal tests were performed with penicilloyl-polylysine, minor determinant mixture, penicillin $\mathrm{G}$, ampicillin, amoxicillin, and with the cephalosporins. RAST used benzylpenicilloyl-polylysine, amoxicilloyl, ampicilloyl-polylysine and the cephalosporin conjugated to polylysine. The results suggested that a small percentage of cephalosporin allergic subjects reacted to penicillin determinants, and most had positive results to determinants generated only by cephalosporins. In a more recent study, the prevalence and risk factors of sensitization to cephalosporin was evaluated in a total of 161 health 
care workers. The ELISA assay measured serum specific IgE antibodies to conjugates of three cephalosporins and HSA. Sensitization rates determined by this technique were $17.4 \%$ for any cephalosporin, $10.4 \%$ for cefotiam, $6.8 \%$ for ceftriaxone and $3.7 \%$ for ceftizoxime (61).

To mention other drugs involved in immediate skin reactions, a case of contact urticaria and anaphylaxis reaction following administration of powder containing clioquinol and bacitracin was described (62) and also immediate hypersensitivity reactions presumably IgE mediated to pyrazolones (63).

\section{Other chemicals}

In plastic industry, workers are in contact with highly reacting chemicals. Cyclic acid anhydrides are synthetic highly reactive LMW compounds widely used as curing agents for epoxy resins and in the production of polyester resins. Commonly used anhydrides are phthalic anhydride, tetrahydrophthalic anhydride, methyl tetrahydrophthalic anhydride, hexahydrophthalic anhydride, methyl hexahydrophthalic anhydride, maleic anhydride and trimellitic anhydride. Cyclic acid anhydrides often cause allergic respiratory diseases, and in the literature only single case reports of contact urticaria of few patients were found. However, recently, occupational contact urticaria has been described by a Finnish study as workers may be exposed in powder or liquid form during manufacturing processes (64). Data are presented for 21 subjects who had been diagnosed with occupational contact urticaria because of exposure to organic acid anhydrides and examined during the period 1990-2006. Prick tests with HSA-acid anhydrides conjugates, RAST determination of specific IgE and open application tests were used for the diagnosis. The majority of the patients had been exposed to an epoxy resin containing methyl hexahydrophthalic anhydride. Specific IgE results were in line with the prick tests and the large reaction was seen for the acid anhydride the patient had been exposed to. Phthalic anhydride $\operatorname{IgE}$ was positive in 19 of 20 patients. Authors conclude that contact urticaria to these compounds may be more common than previously believed, as firstly shown by a previous Finnish study with two patients (65).

Another important constituent of epoxy resins that has been incriminated as producing immediate reactions is bisphenol A for which specific IgE were demonstrated to cause them (66). Similar studies have been reported for another known respiratory allergen, diphenylmethane-4,4'-diisocyanate (67, 68), and for acrylates such as 2-ethylhexyl acrylate, acrylic acid, cyanoacrylates and methyl methacrylate (69).

Contact urticaria to permanent hair dyes such as para-phenylenediamine, which is a very well known skin sensitizer, is almost exclusively reported in consumers, but has also been described in a 
beautician $(70,71)$. Other chemical compounds of LMW reported as inducing ICoU are aliphatic polyamides (72), methyl ethyl ketone, widely used as solvent in plastic manufacture (73) and monoamylamine (74) a vehicle ingredient of topical medicaments.

Finally, metals and metallic salts can also cause occupational contact urticaria. Aluminum (75), chromium, cobalt (76), iridium salts $(77)$, nickel $(75,78)$, platinum salts and rhodium have been reported. Among them, platinum salts are important allergens in the catalyst industry and clinical manifestations may involve both the respiratory system and the skin $(79,80)$. In some cases, an immunological mechanism with specific $\operatorname{IgE}$ is demonstrated $(78,81)$. A RAST was developed for example for the measurement of IgE antibodies specific to platinum chloride complexes in sensitized workers (82).

\section{CONCLUSION}

Numerous LMW chemical compounds may cause contact urticaria, and many of these are encountered in everyday life. Skin clinical manifestations of immediate contact reactions can be expressed as urticaria and/or dermatitis. Both manifestations can be developed by the same patient and can be induced by the same compound simultaneously. Establishing a diagnosis of ICoU is therefore important, in order to confirm the need for allergen avoidance and in view of the potentially life threatening nature of this pathology. Substances responsible for immediate contact skin reactions may be classified by molecular weight, mechanism of action and occupational relevance. Cosmetics, plants, vegetables and food are still the most common agents responsible for new cases of contact urticaria. However, detailed chemical and biological studies continue to be necessary to determine the how and why, and the behavior that provide immunological signs. 


\section{REFERENCES}

1. Giménez-Arnau A, Maurer M, De la Cuadra J, Maibach HI. Immediate contact skin reactions, an update of contact urticaria, contact urticaria syndrome and protein contact dermatitis-“A never ending story”. Eur J Dermatol 2010; 20: 552-562.

2. Fisher AA. Contact Dermatitis. $2^{\text {nd }}$ edn. Philadelphia: Lea \& Febiger, 1973: 283-286.

3. Ale SI, Maibach HI. Occupational contact urticaria. In: Handbook of occupational dermatology (Kanerva L, Elsner P, Wahlberg JE, Maibach HI, eds). Springer-Verlag, Berlin, Heidelberg, 2000: 200-216.

4. Lahti A. Non-immunologic contact urticaria. Acta Dermatovener (Stockholm) 1980; 60 (Suppl. 91): 1-49.

5. Kligman AM. The spectrum of contact urticaria: wheals, erythema and pruritus. Dermatologic Clin 1990; 8: 57-60.

6. Lahti A, Vaananen A, Kokkonen E-L, Hannuksela M. Acetylsalicylic acid inhibits nonimmunologic contact urticaria. Contact Dermatitis 1987; 16: 133-135.

7. Johansson J, Lahti A. Topical non-steroidal anti-inflammatory drugs inhibit non-immunological immediate contact reactions. Contact Dermatitis 1988; 19: 161-165.

8. Wakelin SH. Contact urticaria. Clin Exp Dermatol 2001; 26: 132-136.

9. Amaro C, Goossens A. Immunological occupational contact urticaria and contact dermatitis from proteins: a review. Contact Dermatitis 2008; 58: 67-75.

10. Babilas P, Landthaler M, Szeimies RM. Anaphylactic reaction following hair bleaching. Hautarzt 2005; 56: 1152-1155.

11. Lahti A, Basketter D. Immediate contact reactions. In: Contact Dermatitis, $5^{\text {th }}$ edn (Johansen JD, Frosch PJ, Lepoittevin J-P, eds). Springer-Verlag, Berlin, Heidelberg, 2011: 137-153.

12. Coverly J, Peters L, Whittle E, Basketter DA. Susceptibility to skin stinging, non-immunologic contact urticaria and skin irritation-is there a relationship? Contact Dermatitis 1998; 38: 90-95.

13. Vigan M. Urticaire de contact aux cosmétiques. In: Progrès en Dermato-Allergologie, Tome XIII, John Libbey Eurotext, 2007: 17-34.

14. Cancian M, Fortina AB, Peserico A. Contact urticaria syndrome from constituents of balsam of Peru and fragrance mix in a patient with chronic urticaria. Contact Dermatitis 1999; 41: 3000.

15. Larsen WG. Perfume dermatitis. A study of 20 patients. Arch Dermatol 1977; 113: 623-627.

16. Frosch PJ, Pirker C, Rastogi SC, Andersen K, Bruze M, Svedman C, Goossens A, White IR, Uter W, Giménez-Arnau E, Lepoittevin J-P, Menné T, Johansen JD. Patch testing with a new fragrance 
mix detects additional patients sensitive to perfumes and missed by the current fragrance mix. Contact Dermatitis 2005; 52: 207-215.

17. Safford RJ, Basketter DA, Allenby CF, Goodwin BFJ. Immediate contact reactions to chemicals in the fragrance mix and a study of the quenching action of eugenol. Br J Dermatol 1990; 123: 595606.

18. Diba VC, Statham BN. Contact urticaria from cinnamal leading to anaphylaxis. Contact Dermatitis 2003; 48: 119.

19. Forsbeck M, Skog E. Immediate reactions to patch tests with balsam of Peru. Contact Dermatitis 1977; 3: 201-205.

20. Yamamoto A, Morita A, Tsuji T et al. Contact urticaria from geraniol. Contact Dermatitis 2002; 46: 52 .

21. Emonet S, Pasche-Koo F, Perin-Minisini MJ, Hauser C. Anaphylaxis to oxybenzone, a frequent constituent of sunscreens. J Allergy Clin Immunol 2001; 107: 556-557.

22. Papa CM, Shelley WB. Menthol hypersensitivity: diagnostic basophil response in a patient with chronic urticaria, flushing, and headaches. JAMA 1964; 189: 546-548.

23. Emmons WW, Marks JG Jr. Immediate and delayed reactions to cosmetic ingredients. Contact Dermatitis 1985; 13: 258-265.

24. Fryklöf L-E. A note on the irritant properties of sorbic acid in ointments and creams. J Pharm Pharmacol 1958; 10: 719-720.

25. Rietschel RL. Contact urticaria from synthetic cassia oil and sorbic acid limited to the face. Contact Dermatitis 1978; 4: 347-349.

26. Clemmenson $\mathrm{O}$, Hjorth N. Perioral contact urticaria from sorbic acid and benzoic acid in a salad dressing. Contact Dermatitis 1982; 8: 1-6.

27. Agency for Toxic Substances and Disease Registry (ATSDR). 1999. Toxicological profile for formaldehyde. Atlanta, GA: U. S. Department of Health and Human Services, Public Health Service. Available at: http://www.atsdr.cdc.gov/toxprofiles/index.asp (PB/99/166654).

28. Eighth Commission Directive 86/199/EC of 26 March 1986 adapting to technical progress Annexes II, IV and VI to Council Directive 76/768/EC on the approximation of the laws of the Member States relating to cosmetic products. Off J Eur Commun 1986; L149: 38-45.

29. Kireche M, Giménez-Arnau E, Lepoittevin J-P. Preservatives in cosmetics: reactivity of allergenic formaldehyde releasers toward amino acids through breakdown products other than formaldehyde. Contact Dermatitis 2010; 63: 192-202. 
30. Von Krogh G, Maibach HI. Contact Urticaria. In: Occupational skin disease (Adam RM, ed). Grune \& Stratton, New York, 1983: 58-69.

31. Torresani C, Periti I, Beski L. Contact urticaria syndrome from formaldehyde with multiple physical urticarias. Contact Dermatitis 1996; 35: 174-175.

32. Guin JD, Goodman J. Contact urticaria from benzyl alcohol presenting as intolerance to saline soaks. Contact Dermatitis 2001; 45: 182-183.

33. Walker SL, Chalmers RJG, Beck MH. Contact urticaria due to $p$-chloro- $m$-cresol. Br J Dermatol 2004; 151: 927-952.

34. Birnie AJ, English JS. 2-Phenoxyethanol-induced contact urticaria. Contact Dermatitis 2006; 54: 349.

35. Co-Minh HB, Demoly P, Guillot B, Raison-Peyron N. Anaphylactic shock after oral intake and contact urticaria due to polyethylene glycols. Allergy 2007; 62: 92-93.

36. Ophaswongse S, Maibach HI. Alcohol dermatitis: allergic contact dermatitis and contact urticaria syndrome. Contact Dermatitis 1994; 30: 1-6.

37. Jovanovic M, Karadaglic D, Brkic S. Contact urticaria and allergic contact dermatitis to lidocaine in a patient sensitive to benzocaine and propolis. Contact Dermatitis 2006; 54: 124-126.

38. Waton J, Boulanger A, Trechot PH, Schumtz JL, Barbaud A. Contact urticaria from Emla cream. Contact Dermatitis 2004; 51: 284-287.

39. Suzuki T, Kawada A, Yashimoto Y, Isogai R, Aragane Y, Tezuka T. Contact urticaria to ketoprofen. Contact Dermatitis 2003; 48: 284-285.

40. Warner MR, Taylor JS, Leow YH. Agents causing urticaria. Clin Dermatol 1997; 15: 623-635.

41. Lahti A, Oikarinen A, Vinikka L, Ylikorkala O, Hannuksela M. Prostaglandins in contact urticaria induced by benzoic acid. Acta Derm Venereol (Stockh) 1983; 63: 425-427.

42. Morrow JD, Minton TA, Award JA, Roberts LJ. Release of markedly increased quantities of prostaglandin D2 from the skin in vivo in humans following the application of sorbic acid. Arch Dermatol 1994; 130: 1408-1412.

43. Downard CD, Roberts LJ, Morrow JD. Topical benzoic acid induces the increased synthesis of prostaglandin D2 in human skin in vivo. Clin Pharmacol Ther 1995; 74: 441-445.

44. Goossens A, Amaro C, Géraut C. Urticaire et dermatite de contact aux proteins en pathologie professionnelle. Progrès en Dermato-Allergologie. John Libbey Eurotext, Paris, 2007: 57-70.

45. Castanedo-Tardan MP, Jacob SE, Baumann LS. Contact urticaria to cosmetic and toiletry ingredients. Cosmetic Dermatol 2008; 21: 339-346. 
46. Lachapelle JM, Maibach HI. Patch testing. Prick testing. A practical guide. Springer, Berlin, Heidelberg, New York, 2003.

47. Gleich GJ, Yunginger JW. The radioallergosorbent test: a method to measure IgE antibodies, IgG blocking antibodies, and the potency of allergy extracts. Bull N Y Acad Med 1981; 57: 559-567.

48. Dooms-Goossens A, Gevers D, Mertens A, Vanderheyden D. Allergic contact urticaria due to chloramine. Contact Dermatitis 1983; 9: 319-320.

49. Kramps JA, van Toorenenbergen AW, Vooren PH, Dijkman JH. Occupational asthma due to inhalation of chloramine-T. II. Demonstration of specific IgE antibodies. Int Arch Allergy Appl Immunol 1981; 64: 428-438.

50. Kanerva L, Alanko K, Estlander T, Sihvonen T, Jolanki R. Occupational allergic contact urticaria from chloramine-T solution. Contact Dermatitis 1997; 37: 180-181.

51. Sinaiko R, Heinemann C, Maibach HI. Contact urticaria and anaphylaxis to Chlorhexidine. In: Dermatotoxicology (Zhai H, Wilhelm KP, Maibach HI, eds). CRC Press, 2007: 485-495.

52. Nagendran V, Wicking J, Ekbote A, Onyekwe T, Garvey LH. Ig-E mediated chlorhexidine allergy: a new occupational hazard? Occup Med 2009; 59: 270-272.

53. Ogawa M, Nishinakagawa S, Yokosawa F, Yoshida T, Endo Y. Formaldehyde-specific IgEmediated urticaria due to formaldehyde in a room environment. Japanese $\mathbf{J}$ of Occup Med and Traumatol JJOMT 2009; 57: 125-129.

54. Arroliga ME, Pien L. Penicillin allergy: consider trying penicillin again. Cleveland Clinic J Med 2003; 70: 313-326.

55. Nola RC, Puy R, Deckert K, O’Hehir RE, Douglass JA. Experience with a new commercial skin testing kit to identify IgE-mediated penicillin allergy. Int Med J 2008; 38: 357-367.

56. Worrall GJ, Hull C, Briffet E. Radioallergosorbent test for penicillin allergy in family practice. Can Med Assoc J 1994; 150: 37-41.

57. Torres MJ, Mayorga C, Pamies R, Rodriguez JL, Juarez C, Romano A, Blanca M. Immunologic response to different determinants of benzylpenicillin, amoxicillin, and ampicillin. Comparison between urticaria and anaphylactic shock. Allergy 1999; 54: 936-943.

58. Cetinkaya F, Ozturk AO, Kutluk G, Erdem E. Penicillin sensitivity amongst hospital nurses without a history of penicillin allergy. J Adv Nurs 2007; 58: 126-129.

59. Torres MJ, Romano A, Mayorga C, Moya MC, Guzman AE, Reche M, Juarez C, Blanca M. Diagnostic evaluation of a large group of patients with immediate allergy to penicillins: the role of skin testing. Allergy 2001; 56: 850-856. 
60. Romano A, Mayorga C, Torres MJ, Artesani MC, Suau R, Sanchez F, Perez E, Venuti A, Blanca M. Immediate allergic reactions to cephalosporins: cross-reactivity and selective responses. J Allergy Clin Immunol 2000; 106: 1177-1183.

61. Kim JE, Kim SH, Jin HJ, Hwang EK, Kim JH, Ye YM, Park HS. IgE sensitization to cephalosporins in health care workers. Allergy Asthma Immunol Res 2012; 4: 85-91.

62. Palungwachira P. Contact urticaria syndrome and anaphylactoid reaction from topical clioquinol and bacitracin (Banocin): a case report. J Med Assoc Thai 1991; 74: 43-47.

63. Levy M. Hypersensitivity to pyrazolones. Thorax 2000; 55 (Suppl 2): S72-S74.

64. Helaskoski E, Kuuliala O, Aalto-Korte K. Occupational contact urticaria caused by cyclic acid anhydrides. Contact Dermatitis 2009; 60: 214-221.

65. Tarvainen K, Jolanki R, Estlander T, Tupasela O, Pfäffli P, Kanerva L. Immunologic contact urticaria due to airborne methyl hexahydrophthalic and methyl tetrahydrophthalic anhydrides. Contact Dermatitis 1995; 32: 204-209.

66. Kanerva L, Jolanki R, Tupasela O, Halmepuro L, Keskinen H, Estlander T, Sysilampi ML. Immediate and delayed allergy from epoxy resins based on diglycidyl ether of bisphenol A. Scand J Work Environ Health 1991; 17: 208-215.

67. Kanerva L, Grenquist-Nordén B, Pirilä P. Occupational IgE-mediated contact urticaria from diphenylmethane-4,4'-diisocynate (MDI). Contact Dermatitis 1999; 41: 50-51.

68. Valks R, Conde-Salazar L, Lopez Barrantes O. Occupational allergic contact urticaria and asthma from diphenylmethane-4,4'-diisocynate. Contact Dermatitis 2003; 49: 166-167.

69. Kanerva L, Tokannen J, Jolanki R, Estlander T. Statistical data on occupational contact urticaria. Contact Dermatitis 1996; 35: 229-233.

70. Le Coz CJ. Les intolerances aux teintures capillaires et leur mise au point allergologique. In: Progrès en Dermato-Allergologie, Tome XIII, John Libbey Eurotext, 2007: 99-129.

71. Edwards EK Jr, Edwards EK. Contact urticaria and allergic contact dermatitis caused by paraphenylenediamine. Cutis 1984; 34: 87-88.

72. Winton GB, Lewis CW. Contact urticaria. Int J Dermatol 1982; 21: 573-578.

73. Varigos GA, Nurse DS. Contact urticaria from methyl ethyl ketone. Contact Dermatitis 1986; 15: 259-260.

74. Grahame A. Management of chronic urticaria. Can Fam Physician 1987; 33: 378-384.

75. Helgesen AL, Austad J. Contact urticaria from aluminium and nickel in the same patient. Contact Dermatitis 1997; 37: 303-304. 
76. Kreciscz B, Kiec-Swierczynska M, Krawczyk P, Chomiczewska D, Palczynski C. Cobalt-induced anaphylaxis, contact urticaria and delayed allergy I a ceramics decorator. Contact Dermatitis 2009; 60: $173-174$.

77. Bergman A, Svedberg U, Nilsson E. Contact urticaria with anaphylactic reactions caused by occupational exposure to iridium salt. Contact Dermatitis 1995; 32: 14-17.

78. Estlander T, Kanerva L, Tupasela O, Keskinen H, Jolanki R. Immediate and delayed allergy to nickel with contact urticaria, rhinitis, asthma and contact dermatitis. Clin Exp Allergy 1993; 23 : 306-310.

79. Cristaudo A, Sera F, Severino V, De Rocco M, Di Lella E, Picardo M. Occupational hypersensitivity to metal salts, including platinum, in the secondary industry. Allergy 2005; 60: 159-164.

80. Schena D, Barba A, Costa G. Occupational contact urticaria due to cisplatin. Contact Dermatitis 1996; 34: 220-221.

81. Templeton DM. Mechanisms of immunosensitization to metals. Pure Appl Chem 2004; 76: 12551268.

82. Cromwell O, Pepys J, parish WE, Hughes EG. Specific IgE antibodies to platinum salts in sensitized workers. Clin Allergy 1979; 9: 109-117. 
Table 1. Chemical compounds reported as triggering immediate contact reactions and NICoU $(1,11)$

\begin{tabular}{|c|c|c|c|}
\hline Fragrances-Cosmetics & Biocides-Preservatives & Drugs & Other \\
\hline$\alpha$-Amyl cinnamic aldehyde ${ }^{1}$ & Alcohols (amyl, ethyl, & Acetylsalicylic acid* & Acetic acid* \\
\hline Anisyl alcohol & propyl, isopropyl, & Aminophenazone* & Butylhydroxytoluol* \\
\hline Balsam of Peru & benzyl)* & Amoxicillin* & Chloroform \\
\hline Benzaldehyde & Benzoic acid & Benzocain* & Diethylfumarate* \\
\hline Benzophenone & Bronopol & Capsaicin & Dimethylammonium \\
\hline Cassia oil & Camphor & Chlorpromazine* & chloride* \\
\hline Cetyl alcohol (emulsifier)* & Chlorocresol & Dinitrochlorobenzene* & Dimethyl sulfoxide \\
\hline Cinnamic acid & Formaldehyde & Ketoprofen* & Fumaric acid* \\
\hline Cinnamic alcohol $^{1}$ & Imidazolidinyl urea & Lidocaine* & Panthenol* (hair product) \\
\hline Cinnamic aldehyde $^{1}$ & Kathon CG & Nicotinic acid esters & Polypropylène* \\
\hline Cinnamon oil* & 2-Phenoxyethanol* & Pilocarpine* & Trichloroethanol* \\
\hline Coumarin & Polyethyleneglycol* & Propyphenazone* & Turpentine (plant derivative) \\
\hline Eugenol $^{1}$ & Sodium benzoate & Promethazine* & Vinyl pyridine* \\
\hline Geraniol $^{1}$ & Sorbic acid & Steroids* & Xylene* \\
\hline \multicolumn{4}{|l|}{ Hydroxycitronellal $^{1}$} \\
\hline Isoeugenol $^{1}$ & & & Metals \\
\hline Menthol & & & Aluminum* \\
\hline Propylene glycol & & & Copper* \\
\hline Pyrrolidone carboxylate & & & Gold* \\
\hline Resorcinol & & & Palladium* \\
\hline Stearyl alcohol (emulsifier)* & & & Rhodium \\
\hline \multirow[t]{3}{*}{ Vanillin } & & & Ruthenium \\
\hline & & & Tin \\
\hline & & & Zinc \\
\hline
\end{tabular}

* Immediate contact reaction, unclassified non-immunological/immunological

${ }^{1}$ Constituent of the Fragrance Mix I 
Table 2. Chemical compounds reported as triggering immunological immediate contact reactions/ICoU $(1,11)$

\begin{tabular}{|c|c|c|c|}
\hline Fragrances-Cosmetics & Biocides-Preservatives & Drugs & Other \\
\hline $\begin{array}{l}\text { Allantoin }{ }^{1} \\
\text { Polysorbates } \\
\text { (emulsifier) }^{1} \\
\text { Sorbitan monolaurate }^{(\text {emulsifier) }} \\
\text { Sorbitan monostearate }^{1} \text { (emulsifier) }^{1} \\
\text { Sorbitan sesquiolate } \\
\text { (emulsifier) }^{1} \\
\text { Wool alcohol }^{1}\end{array}$ & $\begin{array}{l}\text { Ammonia } \\
\text { Butylated-hydroxytoluene }^{1} \\
\text { Chloramine } \\
\text { Chlorhexidine } \\
\text { Chlorocresol } \\
\text { Formaldehyde } \\
\text { Mercurochrome } \\
\text { Parabens }{ }^{1} \\
\text { Phenyl mercuric acetate } \\
\text { Phenyl mercuric } \\
\text { propionate } \\
\text { Sodium hypochlorite }\end{array}$ & $\begin{array}{l}\text { Aescin }{ }^{1} \\
\text { Albendazole } \\
\text { Ampicillin } \\
\text { Azithromycin } \\
\text { Bacitracin } \\
\text { Benzoyl peroxide } \\
\text { Cephalosporins } \\
\text { Cisplatin } \\
\text { Chloramphenicol } \\
\text { Diphenylcyclopropenone } \\
\text { Donezepil } \\
\text { Gentamycin } \\
\text { Iodochlorhydroxyquin } \\
\text { Levopromazine } \\
\text { Lindane } \\
\text { Mechlorethamine } \\
\text { Methamizole } \\
\text { Mezlocillin } \\
\text { Neomycin } \\
\text { Penicillins } \\
\text { Pentamidine isothionate } \\
\text { Phenotiazides } \\
\text { Pyrazolones } \\
\text { Rifamycin } \\
\text { Streptomycin } \\
\text { Sulbactam } \\
\text { Virginiamycin }\end{array}$ & $\begin{array}{l}\text { Acetyl acetone } \\
\text { Acid anhydrides } \text { Acrylic acid }^{1} \\
\text { Acrylic monomers } \\
\text { Aliphatic polyamide } \\
\text { p-Aminodiphenylamine (dye) } \\
\text { Aminothiazole }^{1} \\
\text { Aziridine } \\
\text { Basic blue } 99 \text { (hair dye) } \\
\text { Benzonitrile } \\
\text { Bisphenol A } \\
\text { Carbamates } \\
\text { Chlorothalonil } \\
\text { Colophony (plant derivative) } \\
\text { Diethyltoluoamine } \\
\text { Dibutylphthalate } \\
\text { Di-(2-ethylhexyl) phthalate } \\
\text { Diphenylmethane-4,4'- } \\
\text { diisocyanate } \\
\text { Epoxy resins } \\
\text { Formaldehyde resin } \\
\text { Methyl ethyl ketone } \\
\text { Monoamylamine } \\
\text { Nylon } \\
\text { p-Phenylenediamine (hair dye) } \\
\text { Metals } \\
\text { Chromium } \\
\text { Cobalt } \\
\text { Iridium } \\
\text { Mercury } \\
\text { Nickel } \\
\text { Platinum salts (Cisplatin) }\end{array}$ \\
\hline
\end{tabular}

${ }^{1}$ Described as (?) 